CrossMark <click for updates

Cite this: J. Mater. Chem. B, 2016, 4, 7718

\section{High performance free-standing films by layer-by-layer assembly of graphene flakes and ribbons with natural polymers $\dagger$}

\author{
D. Moura, ${ }^{a b c}$ S. G. Caridade, ${ }^{a b}$ M. P. Sousa, ${ }^{a b}$ E. Cunha, ${ }^{c}$ H. C. Rocha, ${ }^{a b c}$ \\ J. F. Mano, ${ }^{a b}$ M. C. Paiva ${ }^{c}$ and N. M. Alves*ab
}

\begin{abstract}
In this work, novel free-standing (FS) films based on chitosan, alginate and graphene oxide (GO) were developed through layer-by-layer assembly. First, GO was synthesized from graphite and multi-walled carbon nanotubes using a modified Hummer's method, yielding oxidized graphene flakes (o-GFs) and oxidized graphene nanoribbons (o-GNRs), respectively, which were then characterized. Then FS films were produced and their morphological, thermal and mechanical properties, as well as the o-GF and o-GNR dispersion along the films were assessed. Their degradation and swelling profiles as well as their biological behavior were evaluated. Graphite and nanotubes were successfully oxidized and exfoliated forming stable suspensions that could be combined with chitosan (CHI) and alginate (ALG) solutions by layer-by-layer processing. The addition of o-GFs and o-GNRs resulted in rougher, hydrophilic FS films with significantly improved mechanical properties relative to CHI/ALG films. The presence of o-GFs or o-GNRs did not affect the thermal stability and the addition of O-GFs resulted in films with enhanced cytocompatibility. The results demonstrate the high potential of the GO reinforced films for biomedical applications, in particular O-GF films, for wound healing, and cardiac and bone engineering applications.
\end{abstract}

Received 9th September 2016, Accepted 4th November 2016

DOI: $10.1039 / c 6 t b 02344 d$

www.rsc.org/MaterialsB

\section{Introduction}

Graphene, a monolayer of $\mathrm{sp}^{2}$ carbon atoms bonded in a hexagonal lattice, is the building block of other carbon allotropes such as nanotubes and graphite. ${ }^{1,2}$ It is characterized by an elastic modulus of approximately $1 \mathrm{TPa}$, an intrinsic electrical conductivity of $6 \times 10^{5} \mathrm{~S} \mathrm{~m}^{-1}$, a thermal conductivity of $5.1 \times$ $10^{3} \mathrm{~W} \mathrm{~m}^{-1} \mathrm{~K}^{-1}$ and a theoretical specific area of $2630 \mathrm{~m}^{2} \mathrm{~g}^{-1} \cdot{ }^{3-5}$ These characteristics make graphene and its derivatives interesting for a wide range of applications, including in the biomedical field, such as biosensing, ${ }^{6,7}$ drug and gene delivery, ${ }^{8,9}$ and tissue engineering. ${ }^{10,11}$

Graphene oxide (GO) based materials such as oxidized graphene flakes (o-GFs) and oxidized graphene nanoribbons (o-GNRs) are cost-effective and large scale derivatives of graphite and multi-walled nanotubes (MWNTs) obtained by oxidation,

\footnotetext{
${ }^{a} 3$ B's Research Group - Biomaterials, Biodegradables and Biomimetics, University of Minho, Headquarters of the European Institute of Excellence on Tissue Engineering and Regenerative Medicine, AvePark - Parque de Ciência e Tecnologia, Zona Industrial da Gandra, Barco, 4805-017, Guimarães, Portugal. E-mail: nalves@dep.uminho.pt; Fax: +351 253510 909; Tel: +351 510904

${ }^{b}$ ICVS/3B's - PT Government Associate Laboratory, Braga/Guimarães, Portugal ${ }^{c}$ Institute for Polymers and Composites/I3N, Department of Polymer Engineering, University of Minho, 4800-058 Guimarães, Portugal

$\dagger$ Electronic supplementary information (ESI) available. See DOI: 10.1039/c6tb02344d
}

capable of partly regenerating graphene after a reduction process. ${ }^{12}$ GO has remarkable properties even before reduction; it is hydrophilic and soluble in water and polar solvents, ${ }^{13,14}$ and has low nanotoxicity, ${ }^{15}$ a large specific surface area and a large concentration of functional groups such as epoxy, hydroxyl, carboxyl and carbonyl groups, ${ }^{14,16,17}$ retaining good mechanical properties. The presence of these groups is advantageous for the interfacial interaction between GO and the polymer matrix, resulting in a strong nanocomposite material, particularly when the nanofiller is homogeneously dispersed in the polymeric matrix. ${ }^{18}$ Graphene and GO are promising materials for biomedical applications, providing physical and chemical conditions for the development of new tissues capable of influencing the proliferation and differentiation of different cells, mimicking the structure and the function of the extracellular matrix. ${ }^{19,20}$

Natural polymers have been explored and used for health care applications due to their great similarity to the extracellular matrix (ECM) and biodegradability properties. ${ }^{21,22}$ Chitosan (CHI) is a nontoxic, antibacterial, antifungal, mucoadhesive, haemostatic and biocompatible polysaccharide. ${ }^{23,24}$ Alginate (ALG) is a hydrophilic, biocompatible and non-immunogenic polysaccharide with the ability to absorb 200 to 300 times more water than its own weight. ${ }^{25,26}$ Both materials are widely explored for biomedical purposes, including as wound dressing materials, ${ }^{27}$ drug release vehicles, ${ }^{28}$ and as ECM models for biological studies. ${ }^{17}$ 
Layer-by-Layer (LbL) assembly is a simple technique to obtain materials with a nanometer scale control of the size, morphology and molecular structure. ${ }^{29}$ It is based on the sequential adsorption of oppositely charged macromolecules onto a substrate surface, typically via electrostatic forces. ${ }^{29}$ Depending on the substrate, different structures may result, including free-standing (FS) films. The use of substrates with low surface energy is a practical approach to achieve robust multilayer FS films without using any sacrificial or dissolution layer. ${ }^{30}$ The use of CHI and ALG for FS film production has been studied by several authors. For example, Martins et al. produced biocompatible CHI/ALG films through LbL assembly. ${ }^{31}$ Caridade et al. developed CHI/ALG FS films ${ }^{32}$ that could be loaded with bone morphogenetic protein $2 .^{33}$

A major drawback in the application of natural polymers is their low mechanical performance. GO has emerged as an inorganic filler capable of providing a better mechanical performance when embedded into such polymeric matrices. Ionita et al. reported a significant improvement in the mechanical and thermal degradation properties of ALG/GO films obtained by a solvent casting method. ${ }^{17}$ Cellulose/GO films obtained by LbL assembly presented good homogeneity, resulting in an increase of the hardness and Young's modulus. ${ }^{34}$ Justin et al. studied the effect of GO in a CHI polymeric matrix, reporting an increase in the ultimate composite tensile strength for GO contents between $0.25 \mathrm{wt} \%$ and $2 \mathrm{wt} \%{ }^{35} \mathrm{Li}$ et al. prepared genipin-crosslinked $\mathrm{CHI} / \mathrm{GO}$ films by solvent casting and found an enhancement of the mechanical and degradation properties along with an improved cytocompatibility. ${ }^{36}$ Research concerning the use of GO as a reinforcement of biopolymers has been published, ${ }^{17,37-41}$ however to the best of our knowledge this is the first report on films prepared with natural polymers such as CHI and ALG assembled with GO through the LbL technique to obtain FS films. The present study aims at developing (CHI/ALG/CHI/GO) $)_{100}$ FS films through the LbL self-assembly technique where o-GFs and o-GNRs are used as nanofillers to reinforce the intrinsic properties of the polymeric matrix. Also, it is intended to compare the change in the properties of CHI/ALG LbL films already developed by distinct authors ${ }^{31-33}$ when a third component, namely o-GFs or o-GNRs, is introduced into the LbL structure. o-GFs and o-GNRs present similar chemical characteristics but flake and ribbon morphologies, respectively. While the chemistry favours a strong interface with ALG and CHI for both reinforcement types, the flake morphology may play a role in the stability of the GO at the polymer surface, in the distribution of the material deposited on each layer, and thus in its reinforcing effectiveness. Depending on the filler, the produced FS films may be potentially used in different biomedical applications such as tissue engineering, wound healing and drug delivery. Initially, the produced GO was characterized by Ultraviolet-Visible (UV-Vis) Spectroscopy, Fourier Transform Infrared (FTIR) Spectroscopy, Raman Spectroscopy and Thermogravimetric Analysis (TGA). Then, the build-up of the multilayered films was investigated in situ by quartz crystal microbalance with dissipation monitoring (QCM-D). Thereafter, the FS films were produced and characterized by Scanning Electron Microscopy (SEM), Atomic Force
Microscopy (AFM), TGA and Raman mapping. The mechanical performance, wettability, water uptake, degradation and biological behavior of the obtained FS films were also explored.

Thus, the present research work provides new insights into the materials field, once the combination of CHI, ALG and GO in the production of FS films is new. Furthermore, the effect that different graphene oxide sources may have on the final properties of the composite was also explored for the first time. Also, the LbL technique used in this work, different from the methods that have been typically used to produce films, such as vacuum assisted flocculation or casting methods allows us to have an enhanced control over the film properties.

\section{Results and discussion}

\section{Structural characterization of the oxidized carbon nanoparticles}

The characterization of the different oxidized carbon nanoparticles was performed using distinct techniques. The UV-Vis spectroscopy and FTIR results of these materials are provided in the ESI $\dagger$ (Section S1).

Raman spectra are presented in Fig. 1(a) and (b), showing the major peaks typical of graphite-related materials. The D band, near $1350 \mathrm{~cm}^{-1}$, is due to disorder in the $\mathrm{sp}^{2}$ carbon lattice of graphene atoms, induced by their oxidation; ${ }^{3,42}$ the $\mathrm{G}$ band at $1580 \mathrm{~cm}^{-1}$ is assigned to the $\mathrm{E}_{2 \mathrm{~g}}$ phonon mode of graphite, and results from the in-plane bond-stretching motion of the ordered $\mathrm{sp}^{2}$ bonded carbon atoms; ${ }^{43,44}$ and the $2 \mathrm{D}$ band at $2700 \mathrm{~cm}^{-1}$ results from the second order Raman scattering..$^{42}$

Oxidized exfoliated graphite (o-EG) and oxidized multi-walled carbon nanotubes (o-MWNTs) are characterized by broader D
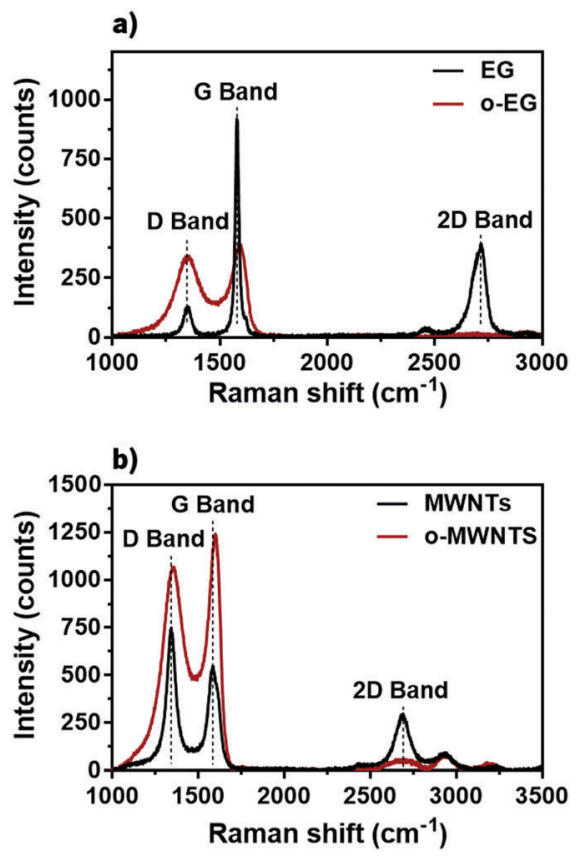

Fig. 1 (a) and (b) Raman spectra obtained for O-EG and pristine EG, and o-MWNTs and pristine MWNTs, respectively. 
and $\mathrm{G}$ bands compared to the pristine materials. For EG an increase in $\mathrm{D}$ band intensity is observed after oxidation, related to the increase in the structural defect content caused by the oxidation process, and consequently a reduction of the in-plane $\mathrm{sp}^{2}$ character. The intensity ratio of these two peaks $\left(I_{\mathrm{D}} / I_{\mathrm{G}}\right)$ increased from 0.12 to 0.85 . The MWNTs show an inverse behavior, with a decrease of $I_{\mathrm{D}} / I_{\mathrm{G}}$ from 1.38 to 0.84 in the oxidized material. The different behavior observed for the MWNTs may be explained by the high concentration of defects in the pristine form, caused mostly by the production technique. After oxidation, the resulting o-MWNTs are shortened with most of the impurities and defects present on the edges. The 2D band of both EG and MWNTs decreases in the intensity and almost disappears after oxidation. This is indicative of a significant loss of regular hexagonal $\mathrm{sp}^{2}$ carbon lattices after oxidation. Besides, it reveals that both materials lost their carrier mobility, as suggested by Zhu et al. ${ }^{45}$

The stability of the aqueous suspensions was characterized by zeta potential $(\zeta)$ measurements. o-GFs present a zeta value of $-49 \pm 9 \mathrm{mV}$ and o-GNRs of $-37 \pm 8 \mathrm{mV}$. According to the literature these $\zeta$ values indicate that both o-GFs and o-GNRs are capable of forming stable suspensions in water, aided by the electrostatic repulsion between the particles due to the negative charge, caused by the ionization of the carboxylic and phenolic groups under basic $\mathrm{pH}$ conditions. ${ }^{46,47}$

\section{QCM-D results}

QCM-D was used to prove if the assembly of the multilayered films, in particular of the CHI/o-GF and CHI/o-GNR layers, was possible. As shown in Fig. 2(a), the decrease of the resonant

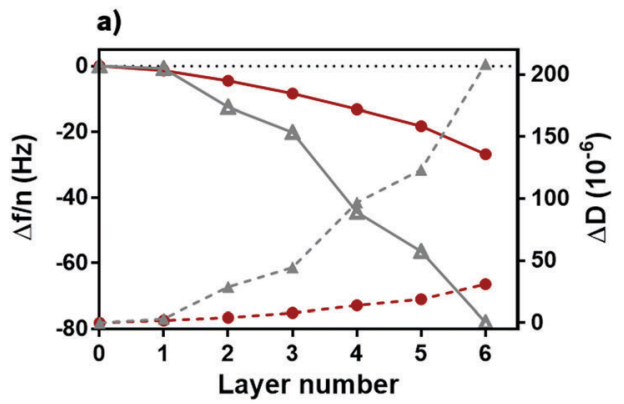

b)

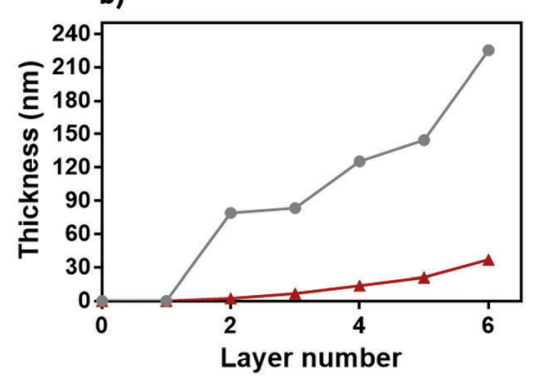

Fig. 2 (a) QCM-D results showing the build-up of the CHI/O-GF (grey line) and $\mathrm{CHI} / \mathrm{O}-\mathrm{GNR}$ (red line) films as a function of the layer number. The normalized frequency $(\Delta f)$ is represented by the empty triangles and circles, and the dissipation $(\Delta D)$ by the full triangles and circles; (b) thickness as a function of the layer number of CHI/O-GF (grey line) and CHI/O-GNR (red line) multilayer films, using a Voigt based model. frequency $((\Delta f) / n)$ indicates that after either CHI or o-GF or o-GNR deposition the polyelectrolyte (PE) adsorbs onto the crystal surface. Comparing both formulations, it is clearly seen that the o-GF containing films show the highest frequency decrease and at the same time higher dissipation $(\Delta D)$, which reveals that these films may present a higher shear modulus. Nevertheless, the sequential deposition process was successfully achieved with both film formulations, i.e. a stable and reproducible behavior was observed with the possibility to obtain thicker films. Based on these results, it is found that $(\mathrm{CHI} / \mathrm{ALG} / \mathrm{CHI} / \mathrm{GO})_{100}$ FS films were then produced as described in the Experimental section. As CHI is positively charged whereas ALG and GO are negatively charged, only $\mathrm{CHI}$ interfaces with GO in the FS films, taking into account the fact that the LbL assembly typically consists of a sequential adsorption of oppositely charged materials.

The thickness of each layer was also estimated, Fig. 2(b), and it was found that o-GF films tend to be thicker than the o-GNR films, since at the end of the third bilayer a thickness of 225 and $40 \mathrm{~nm}$ was achieved for each film, respectively.

\section{SEM analysis}

The morphology of both sides of the FS films as well as their cross-section was analyzed by SEM. All the films were easily removed from the polypropylene (PP) substrate and demonstrated an easy handling. SEM images revealed a higher roughness for the upper side of the films, Fig. $3\left(a_{1}\right),\left(b_{1}\right)$ and $\left(c_{1}\right)$, when compared to the surface in contact with the substrate, Fig. $3\left(a_{2}\right),\left(b_{2}\right)$ and $\left(c_{2}\right)$, which has already been described. ${ }^{32}$ The roughness of the side in contact with the substrate increases in the FS films that contain o-GFs and o-GNRs, which was attributed to the particles embedded in the polymeric matrix, as also found by Ionita et al. ${ }^{17}$ Nevertheless, these FS films still exhibit a flat morphology that could be an important characteristic to achieve adhesive properties and thus, to strengthen the adhesion to medical devices or even to anatomic structures such as bone. ${ }^{17,48}$ The addition of o-GFs resulted in less porous films compared to the controls
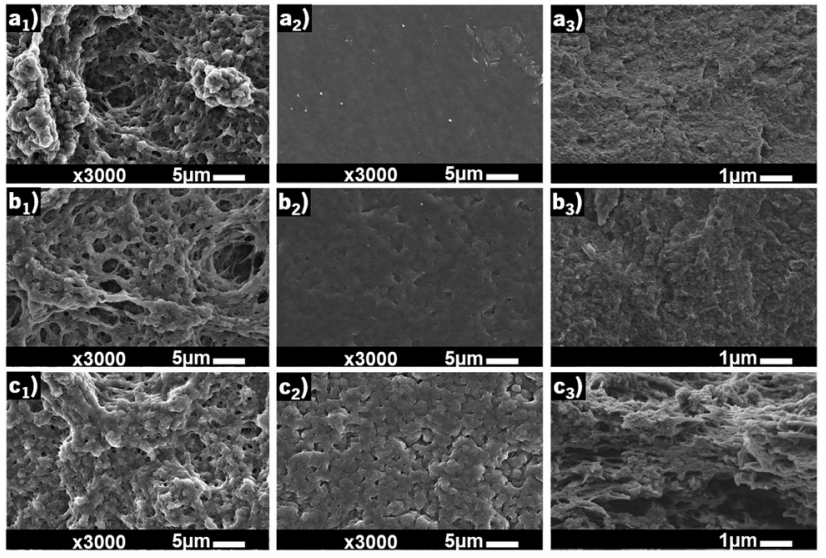

Fig. 3 SEM images of $\left(a_{1}\right)$ upper side and $\left(a_{2}\right)$ substrate side of the $(\mathrm{CHI} /$ ALG/CHI/ALG) 100 FS film; $\left(b_{1}\right)$ upper side and $\left(b_{2}\right)$ substrate side of the (CHI/ALG/CHI/o-GF) $)_{100}$ FS film; $\left(\mathrm{c}_{1}\right)$ upper side and $\left(\mathrm{C}_{2}\right)$ substrate side of the (CHI/ALG/CHI/o-GNR) ${ }_{100}$ FS film. The cross-section of each film is depicted in $\left(a_{3}\right),\left(b_{3}\right)$ and $\left(c_{3}\right)$ micrographs. 
(Fig. 3( $\left.b_{1}\right)$ ) and concerning the cross-section (Fig. $3\left(b_{3}\right)$ ), the SEM images exhibit wrinkle-like structures that were not present in the $(\mathrm{CHI} / \mathrm{ALG} / \mathrm{CHI} / \mathrm{ALG})_{100}$ films, and thus may be assigned to the presence of o-GFs. ${ }^{18}$

The nanocomposite films with o-GNRs, Fig. $3\left(c_{1}\right)$ and $\left(c_{2}\right)$, show a similar morphology, although with less porosity than the previous ones. The cross-section, Fig. $3\left(c_{3}\right)$, reveals that both nanocomposite films have a denser structure, which may arise from the strong interaction between $\mathrm{CHI}$ with o-GFs and o-GNRs, that would result in an expected enhancement of the mechanical properties. Moreover, no exposed o-GF or o-GNR sheets were visualized, which emphasizes the strong interaction with the surrounding CHI/ALG molecules and may also account for the porosity decrease. Similar compact structures obtained by LbL assembly were already observed by other authors. ${ }^{30,33}$ Moreover, the thickness of the films is approximately $50 \mu \mathrm{m}$. In general, all films showed a homogeneous morphology and some porosity, which is important for nutrient and gas diffusion, regarding future applications in the biomedical field.

\section{AFM analysis}

The surface topography of the films (Fig. $4\left(a_{2}\right),\left(b_{2}\right)$ and $\left(c_{2}\right)$ ) was analyzed by AFM. The root-mean-square deviation values of the surface roughness $\left(R_{\mathrm{RMS}}\right)$ for the region represented in Fig. 4(a)-(c) $\left(5 \times 5 \mu \mathrm{m}^{2}\right)$ were evaluated. The $R_{\mathrm{RMS}}$ values (Fig. $\left.4(\mathrm{~d})\right)$ obtained

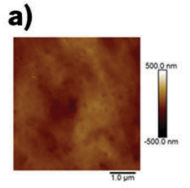

b)

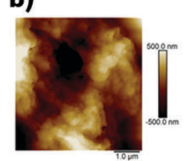

c)

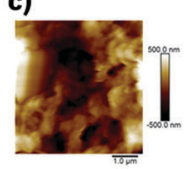

d)
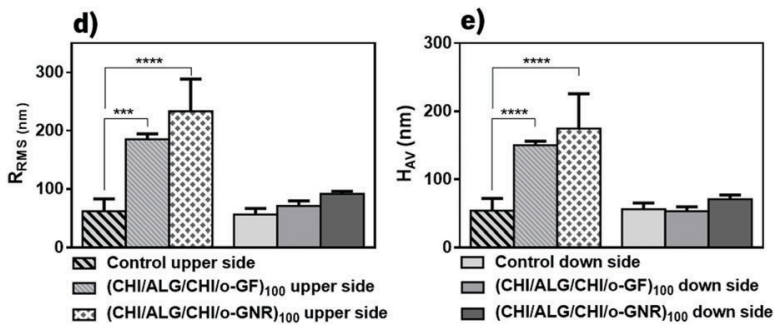

Fig. 4 AFM surface images with respective 3D representation of: controls and FS films ( $a$ and $\left.a_{1}\right),(C H I / A L G / C H I / O-G F)_{100}$ films $\left(b\right.$ and $\left.b_{1}\right)$ and (CHI/ALG/CHI/o-GNR) ${ }_{100}$ films (c and $c_{1}$ ). (d) $R_{\text {RMS }}$ and (e) shows the $H_{\text {AVV }}$. Significant differences are given for $p<0.001{ }^{(* *)}$ and $p<0.0001{ }^{(* * *)}$. The real images of the different film formulations are provided in $\left(a_{2}\right)$, $\left(b_{2}\right)$ and $\left(c_{2}\right)$, respectively. for the controls have shown that the substrate side is flatter, $49 \pm 15 \mathrm{~nm}$, than the upper side of the films, $61 \pm 21 \mathrm{~nm}$. In fact, the roughness increase may be explained by the significant presence of polymeric loops and tails in the upper side of the films, producing rough surface areas, while the side in contact with the substrate, due to its flat topography, will produce a more molecularly smooth surface. ${ }^{49}$ Similar roughness observations were achieved by other authors. ${ }^{30,32}$ When o-GFs and o-GNRs were added to the polymeric matrix, significant changes were visualized. An increase in the roughness of both composite films is clearly visible in Fig. $4\left(b_{1}\right)$ and $\left(c_{1}\right)$, where o-GF films demonstrated to reach a roughness value up to $185 \pm 10 \mathrm{~nm}$ and the o-GNR films up to $224 \pm 65 \mathrm{~nm}$. Such results were expected, especially for o-GNR ones, similar to what happens to CNTs; these structures easily bend or present a twisty morphology, which may result in bundle structures. A similar behavior was described by Gudarzi et al. ${ }^{50}$ The increase in the roughness can result in an improvement of the stiffness, fracture toughness and ductility, once the roughness increase suggests an induced crack deflection.

The average height $\left(H_{\mathrm{AV}}\right)$ values are shown in Fig. 4(e). The $H_{\mathrm{AV}}$ values range from 40 to $170 \mathrm{~nm}$ and, when compared with the $R_{\mathrm{RMS}}$, it is possible to see that the values almost match, indicating that although a roughness area was achieved with the addition of oxidized nanoparticles, the roughness is constant along the films. At last, it is worth mentioning that the surface roughness on the substrate side does not change significantly with the presence of o-GFs and o-GNRs, and for that reason their $2 \mathrm{D}$ and $3 \mathrm{D}$ images were not represented.

\section{Raman mapping}

Raman mapping was performed to analyze the o-GF and o-GNR distribution in the CHI/ALG matrix, Fig. 5(a) and (c), respectively. In order to map the nanoparticle distribution, the integrated intensity was measured over the spectral range of $1500-1700 \mathrm{~cm}^{-1}$, to identify the D and G peaks of the o-GFs and o-GNRs, as shown in Fig. 5(e) and (f). The polymers, ALG and CHI, are not active in the Raman spectrum, and so the only film component that can produce a Raman spectrum is GO. The blue color intensity in Fig. 5(a) and (c) correlates with the concentration of o-GNRs and o-GFs in the film, respectively, higher blue color intensity corresponding to areas with higher $\mathrm{G}$ band intensity. The laser beam penetrates within a thickness of approximately $1 \mu \mathrm{m}$, thus analysing several layers of o-GFs or o-GNRs deposited by LbL assembly. Fig. 5(b) and (d) show the optical micrographs obtained with visible light in reflection mode, depicting the surface area mapped by Raman spectroscopy. The presence of o-GFs and o-GNRs was observed along the FS films, mapping areas of approximately $25 \times 15 \mu \mathrm{m}^{2}$ of at least three different samples of each material, showing its continuous distribution.

\section{TGA}

The thermal stability and the weight composition of o-GFs and o-GNRs containing FS films were evaluated by TGA. Fig. 6(a) illustrates that all the films present a similar initial weight loss 


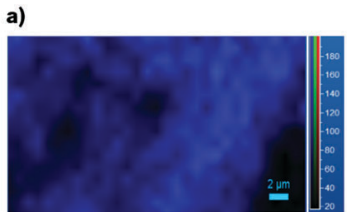

c)
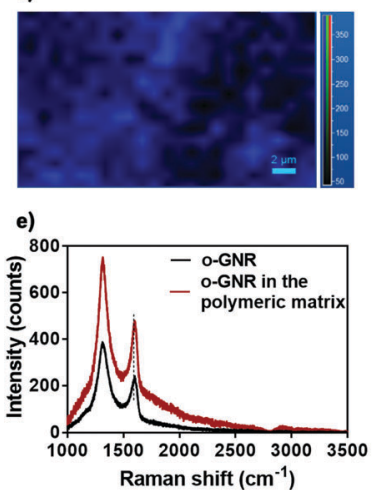

Fig. 5 (a and c) Distribution of o-GNRs and o-GFs (blue) in the polymeric matrix (CHI/ALG) obtained by Raman spectroscopy, with the respective intensity color scale (a.u.); (b and d) optical image of the o-GNR and o-GF composite films; (e and f) Raman spectra obtained for the o-GNRs and o-GFs before (obtained with a $532 \mathrm{~nm}$, black line) and after the dispersion (obtained with a $785 \mathrm{~nm}$ laser, red line) in the (CHI/ALG) matrix, respectively.

that may be related to the elimination of strongly adsorbed water. The total weight loss measured after thermal decomposition, at $800{ }^{\circ} \mathrm{C}$, shows a higher final weight\% when o-GFs and o-GNRs are present, indicating that the fillers were successfully incorporated within the polymers and allowing the approximate quantification of their weight content. The difference in the residual weight measured from the composite with o-GFs to the composite with layered polymers was $\sim 1.6 \mathrm{wt} \%$, while for the o-GNR composite it was $\sim 1.1 \mathrm{wt} \%$. Considering that the o-GFs and o-GNRs alone present a residual weight that may be near 62 and $60 \mathrm{wt} \%$, respectively, when heated to $800{ }^{\circ} \mathrm{C}$ in nitrogen (Fig. S2(a) and (b) in the ESI $\dagger$ ), the weight composition of fillers in the FS films may be estimated to be up to $2.6 \mathrm{wt} \%$ and $1.8 \mathrm{wt} \%$ for o-GFs and o-GNRs, respectively.

The analysis of the thermograms and the corresponding derivative (Fig. 6(a) and (b)) indicates that the thermal stability of the composite films is not affected by the addition of o-GFs and o-GNRs.

\section{Water contact angle (WCA) measurements}

The results of the WCA measurements made for the obtained FS films are depicted in Fig. 7. It is observed that, independent of the side, the control films $(\mathrm{CHI} / \mathrm{ALG} / \mathrm{CHI} / \mathrm{ALG})_{100}$ show a WCA around $100^{\circ}$. This value is similar to the value found by Silva et al. for $\mathrm{CHI} / \mathrm{ALG}$ films, ${ }^{51}$ and could be attributed to a mixed effect of the surface chemistry of films and their topography.

For the FS films containing o-GFs and o-GNRs, two different behaviors are observed. On the down side, it is possible to verify that no significant changes occurred when compared to the control films. This is explained by the presence of the same material layer, CHI. Regarding the upper side, significant changes
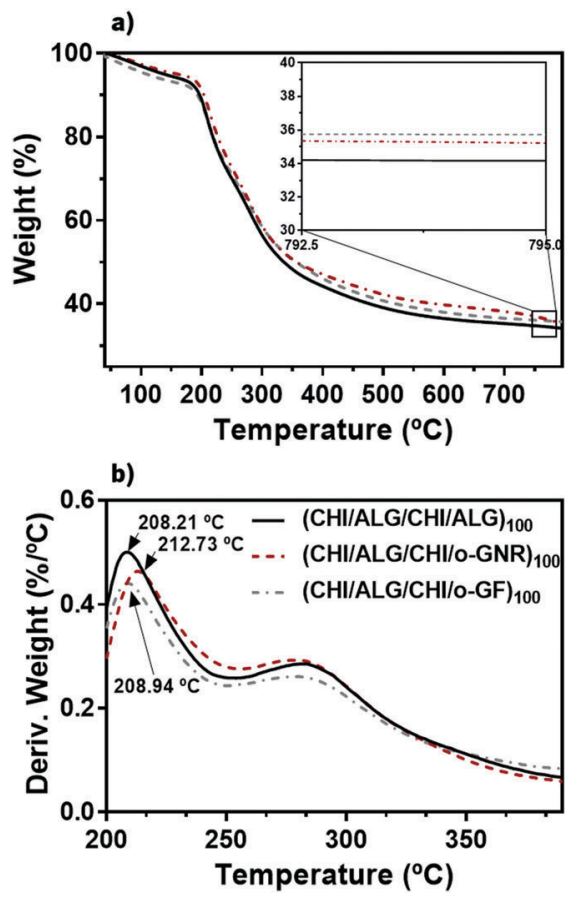

Fig. 6 TGA graphical representation: (a) thermogravimetric (TG) curves with the inset showing a magnification for the temperature range of $792.5-795^{\circ} \mathrm{C}$ and (b) derivative of the weight loss curves (DTG) for all films, as a function of temperature $\left({ }^{\circ} \mathrm{C}\right)$.

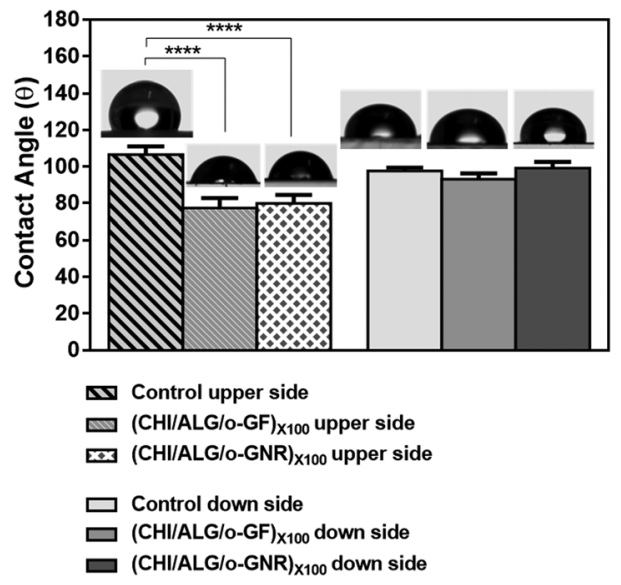

Fig. 7 Water contact angle results with representative images for both sides of all films. Significant differences are given for $p<0.0001\left(^{* * * *}\right)$.

were verified. Both $(\mathrm{CHI} / \mathrm{ALG} / \mathrm{CHI} / \mathrm{o}-\mathrm{GF})_{100}$ and $(\mathrm{CHI} / \mathrm{ALG} / \mathrm{CHI} /$ o-GNR $)_{100}$ show a decrease in the WCA, presenting values of $77.37 \pm 5.51^{\circ}$ and $79.92 \pm 4.54^{\circ}$, respectively. So, the films turned hydrophilic when both forms of GO were added. A low value of WCA $\left(30.7^{\circ}\right)$ for GO was reported, ${ }^{52}$ which is due to the capability of this material to establish hydrogen bonds due to the presence of carboxylate groups. Comparing the upper side of the GO films, it is possible to see that no significant changes occurred, showing that the effects of these groups present on the surface are similar for both oxidized graphene flakes and graphene nanoribbons. 


\section{Swelling ability studies}

The swelling behavior of the produced FS films was evaluated for $48 \mathrm{~h}$ in phosphate buffered saline (PBS) at $37{ }^{\circ} \mathrm{C}-$ Fig. 8 . Concerning the $(\mathrm{CHI} / \mathrm{ALG} / \mathrm{CHI} / \mathrm{ALG})_{100}$ films, the results show that they attain the equilibrium after $3 \mathrm{~h}$ reaching a maximum swelling of approximately $280 \%$. Globally, it is verified that the incorporation of both GO forms into the polymeric matrix reduces the water uptake (WU) of the nanocomposite FS films and more time is necessary to achieve the WU equilibrium. This behavior may result from the lower space for water storage capacity and decrease in the expansion ratio, caused by hydrogen bonding between GO and CHI. The SEM images also corroborate these results (Fig. 3), once a decrease in the porosity was verified when o-GFs and o-GNRs were added, hindering the WU capability. Although the addition of GO led to hydrophilic films, the decrease in the WU could be explained by the bridge between $\mathrm{GO}$ and $\mathrm{CHI}$, in a process similar to the one observed for genipin and CHI. ${ }^{52}$ Thus, the presence of both GO in the CHI/ALG films appears to affect the swelling behavior of the films. This effect shows great ability to replace other cross-linking methods, and therefore to be potentially applied as heart valves or skin scaffolds. ${ }^{36}$

\section{Biodegradation studies}

When implanted in the human body, a biomaterial should be capable of providing a sustainable platform for cell proliferation/differentiation and potential growth and replacement of a tissue. Among several factors, the degradation rate is one of the most important factors, and it is required that the formation of the new tissue matches with the degradation of the material. Lysozyme was used to study the degradation behavior of the FS films. This enzyme is present in different human tissues, cells, and fluids, in different concentrations around $7-13 \mathrm{mg} \mathrm{L}^{-1}$. $^{53}$ For convenience, the maximum concentration was employed during the study.

Fig. 9 indicates that the control FS films always reach a higher and faster weight loss than the nanocomposite films. For the standard degradation assays, performed with PBS medium, both nanocomposite films present a weight loss around $15 \%$ of its initial weight and the degradation is more pronounced in the

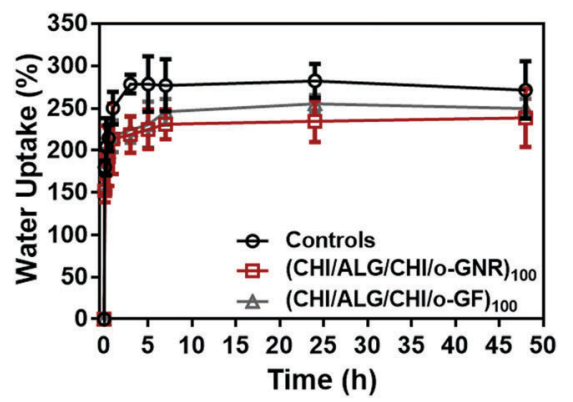

Fig. 8 Variation of the water uptake ability as a function of time of $(\mathrm{CHI} / \mathrm{ALG} / \mathrm{CHI} / \mathrm{ALG})_{100}$ (black round symbol), (CHI/ALG/CHI/o-GF) 100 (grey triangle symbol) and (CHI/ALG/CHI/o-GNR) 100 (red square symbol) in PBS at $37^{\circ} \mathrm{C}$.

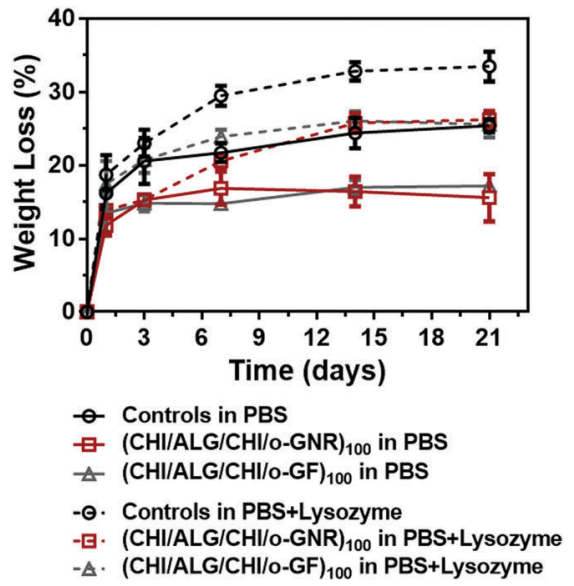

Fig. 9 Degradation behavior of $(\mathrm{CHI} / \mathrm{ALG} / \mathrm{CHI} / \mathrm{ALG})_{100}$ (black round symbol), (CHI/ALG/CHI/o-GF) 100 (grey triangle symbol) and (CHI/ALG/ CHI/O-GNR) 100 (red square symbol) FS films when immersed in PBS or lysozyme over a period of 21 days at $37^{\circ} \mathrm{C}$.

first three days. In turn, the (CHI/ALG/CHI/ALG) ${ }_{100}$ control films possess a weight loss of about $25 \%$ of their initial weight up to 21 days. Higher weight loss values are verified when lysozyme is used as a degradation medium. Although both nanocomposite films present higher degradation in the presence of the enzyme, their weight loss does not exceed the values shown by the control films in PBS. Furthermore, the (CHI/ALG/CHI/ALG) $)_{100}$ films immersed in lysozyme were the more degraded materials, reaching a weight loss of $35 \%$. These results indicate that the incorporation of o-GFs and o-GNRs seems to induce a greater resistance to degradation. This could be related to their water uptake capability. As seen previously, the nanocomposite films possess lower capability to swell and thus, the amount of PBS and enzyme entering into the polymeric matrix is lower, resulting in a lower weight loss. Moreover, the observable weight loss in the nanocomposite films could result from lysozyme immobilization on the GO surface. In fact, the GO surface is rich in functional groups, ${ }^{54}$ which could allow the immobilization of lysozyme through electrostatic interactions, avoiding the degradation of the material.

\section{DMA}

Dynamic mechanical analysis (DMA) experiments were performed to evaluate the effects of the incorporation of GO on the mechanical/viscoelastic properties of the FS films. These experiments were conducted with the samples in the wet state to mimic the conditions of the final applications. In fact, we are envisaging biomedical applications where the materials will be in a hydrated state, e.g. when implanted or used as tissue engineering scaffolds. The variation of the storage modulus $E^{\prime}$ along the frequency is presented in Fig. 10(a). Overall, for all the FS films studied, $E^{\prime}$ increases with frequency as expected. ${ }^{30,33}$ Such behavior is even more pronounced for the FS films containing o-GNRs. Fig. 10(a) shows that the addition of o-GFs and o-GNRs results in an increased stiffness of the films, reaching values 2 times and 4 times higher than the controls, respectively. 

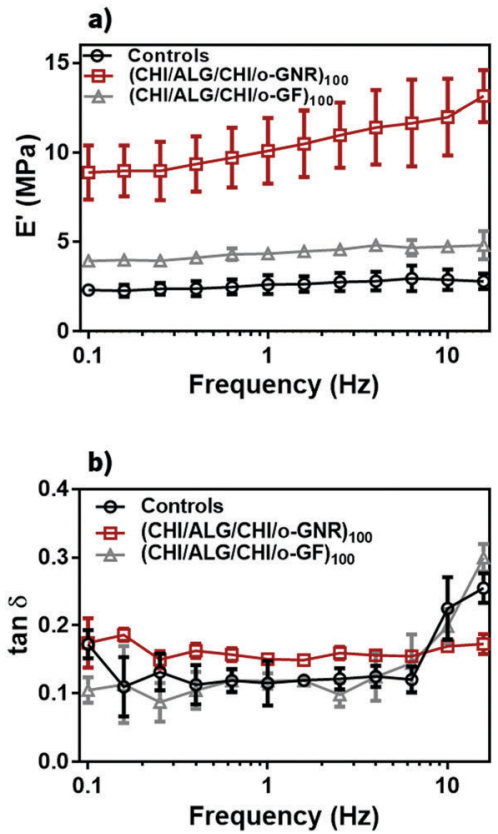

Fig. 10 DMA measurements. Variation of the storage modulus (a) and the loss factor (b) along a frequency scan ranging from $0.1-15 \mathrm{~Hz}$, at $37^{\circ} \mathrm{C}$ of the FS films while immersed in PBS to closely simulate the physiological conditions.

Other authors have already reported an increase in stiffness of approximately 2 times for a graphene-reinforced polymer composite with only $0.1 \mathrm{wt} \%$ of graphene. ${ }^{55}$ These results are in agreement with the water uptake tests, where it was shown that the ability of the nanocomposite films to swell decreases for the composite films.

$\tan \delta$ provides information about the damping properties of the films. It can be seen that $\tan \delta$ is very similar for all FS films, exhibiting a slight increase with the frequency (Fig. 10(b)). The control film and the FS films containing o-GFs presented slightly higher dissipative properties at the higher frequencies, which can be related to their lower stiffness. Moreover, since $\tan \delta$ presents values between 0.1 and 0.3 , the films show a viscoelastic performance, which is important for biomedical applications, since the living tissues and their biological constituents are also viscoelastic. ${ }^{56}$

\section{Tensile tests}

The mechanical behavior of the FS films was also characterized by tensile tests. The ultimate tensile strength (UTS) and strain at failure $\left(\varepsilon_{\mathrm{B}}\right)$ values are presented in Fig. 11(a) and (b), respectively. Fig. 11(a) shows that when the films contained o-GFs, the UTS is around two fold higher than the value that the control sample can achieve. This increase suggests that o-GFs and the polymer matrix are strongly bonded through chemical interactions, such as hydrogen bonds, ${ }^{57}$ and achieve a uniform stress distribution. This is possibly due to the alignment of o-GFs in the polymeric matrix (see SEM analysis), minimizing the presence of stress concentration spots and leading to a stronger material, even with a GO weight content of just $1.8-2.6 \%$.
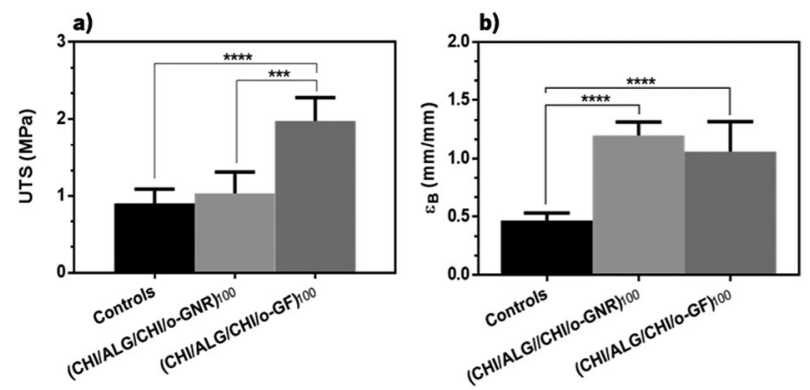

Fig. 11 Representation and comparison of the mechanical properties of controls, and o-GNR and o-GF composite films. (a) Ultimate tensile strength (UTS) and (b) strain at break $\left(\varepsilon_{\mathrm{B}}\right)$. Significant differences were found for $p<0.001^{(* * *)}$ and $p<0.0001^{(* * * *)}$.

The elongation at break, Fig. 11(b), presents a significant difference between the control films and the ones with o-GNRs increasing nearly 2.5 times. This may result from the strong interfacial adhesion between the oxidized nanoparticles and the polymer or could also result from the slippage of the different GO sheets when stress is applied. Thus, a simultaneous increase of the strength, stiffness and ductility of the films can be obtained just by adding low GO fractions, as reported by other authors for similar materials. ${ }^{58,59}$ Also, the values of the mechanical properties of these films are in the range of the ones typically reported for the envisaged biomedical applications, in particular for the regeneration of small tissue defects. ${ }^{60}$ For example, the aorta has an ultimate tensile strength of $0.3-0.8 \mathrm{MPa}$, similar to the control films and to the CHI/ALG/CHI/o-GNR ones, while skin varies between 1 and $20 \mathrm{MPa}$, a range where CHI/ALG/CHI/o-GF films can be found.

\section{Biological assays}

The cytocompatibility of the produced films was evaluated in vitro with L929 cells. To understand how cells adhered to the FS films and which morphology they presented, a 4',6-diamidino-2-phenylindole (DAPI)-phalloidin test was performed (Fig. 12). Comparing all the formulations, it can be noticed that cells behave quite differently for each condition. Although presenting a round shape on day 1 , the cells start to adhere to the films' surface; the $(\mathrm{CHI} / \mathrm{ALG} / \mathrm{CHI} / \mathrm{o}-\mathrm{GNR})_{100}$ formulation is the one that presents less cells attached on their surface. After 3 days, an increase in cell number on controls and (CHI/ALG/CHI/o-GF $)_{100}$ films is seen, where cells are well spread and anchored to the film surface.

However, such an effect is not verified on the (CHI/ALG/CHI/ o-GNR $)_{100}$ films in which no significant changes in the cell density and morphology of the cells are noticed compared to day 1. On day 7, (CHI/ALG/CHI/o-GNR $)_{100}$ films still exhibit poor proliferation, although some cells started to reveal a more elongated shape morphology. On the other hand, $(\mathrm{CHI} / \mathrm{ALG} / \mathrm{CHI} / \mathrm{ALG})_{100}$ and $(\mathrm{CHI} / \mathrm{ALG} / \mathrm{CHI} / \mathrm{o}-\mathrm{GF})_{100}$ films present an increase in cell proliferation, with almost all the surface area being covered by adhered cells, especially for the ones that contain o-GFs. Moreover, after 7 days, the cells on the (CHI/ALG/CHI/o-GF $)_{100}$ FS film show a similar morphology and behavior when compared with tissue culture polystyrene (TCPS). 


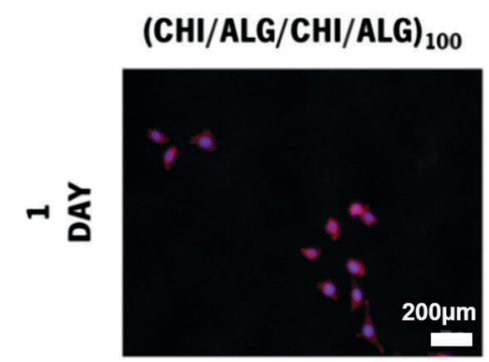

(CHI/ALG/CHI/0-GNR) 100

(CHI/ALG/CHI/o-GF) 100
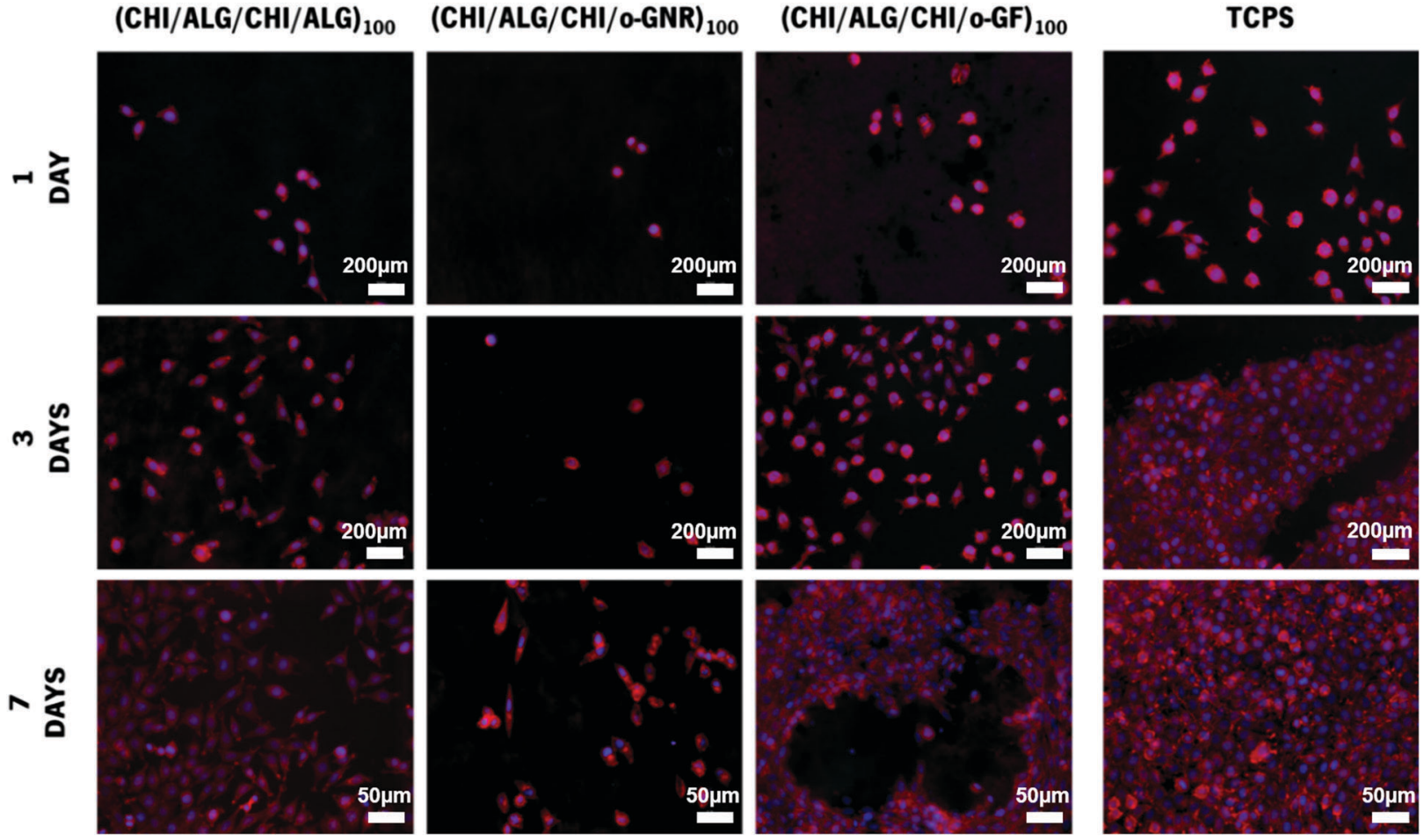

Fig. 12 Evaluation of cells' morphology using DAPI for nuclei staining (blue labeled) and phalloidin for F-actin filament staining (red labeled) by fluorescence microscopy at 1,3 , and 7 days post-seeding on (CHI/ALG/CHI/ALG) $)_{100},(\mathrm{CHI} / \mathrm{ALG} / \mathrm{CHI} / \mathrm{O}-\mathrm{GNR})_{100}$ and $(\mathrm{CHI} / \mathrm{ALG} / \mathrm{CHI} / \mathrm{O}-\mathrm{GF})_{100} \mathrm{FS}$ films.

MTS assays were used to evaluate the cellular viability on the FS films - Fig. 13(a). Overall, all conditions present an increase in cell viability over the time period of the experiments. At day 1, TCPS presents significant differences in relation to the $(\mathrm{CHI} / \mathrm{ALG} / \mathrm{CHI} / \mathrm{o}-\mathrm{GNR})_{100}(p<0.05)$ FS films. At day 3 , TCPS is significantly different from all the FS films $(p<0.0001)$ when comparing it to (CHI/ALG/CHI/ALG) 100 and (CHI/ALG/CHI/ o-GNR $)_{100}$ and $(p<0.001)$ in the case of $(\mathrm{CHI} / \mathrm{ALG} / \mathrm{CHI} / \mathrm{o}-\mathrm{GF})_{100}$. On day 7 , the same differences as day 3 are verified between the TCPS and the FS films. Moreover, at this time point, significant differences could be observed by comparing (CHI/ALG/CHI/ o-GNR $)_{100}$ with $(\mathrm{CHI} / \mathrm{ALG} / \mathrm{CHI} / \mathrm{ALG})_{100}(p<0.01)$ and with $(\mathrm{CHI} / \mathrm{ALG} / \mathrm{CHI} / \mathrm{o}-\mathrm{GF})_{100}(p<0.0001)$. Such results revealed that, concerning the produced films, (CHI/ALG/CHI/o-GF) ${ }_{100}$ is the one that allows cells to express better metabolic activity and (CHI/ALG/CHI/o-GNR) ${ }_{100}$ exhibits lower metabolic activity. The cell proliferation over a period of 7 days was assessed by DNA quantification (Fig. 13(b)). It is possible to verify that all formulations led to an increase in cell proliferation. Comparing all the formulations with TCPS at day 1, significant differences are observed for $(\mathrm{CHI} / \mathrm{ALG} / \mathrm{CHI} / \mathrm{ALG})_{100}(p<0.05)$ and for $(\mathrm{CHI} / \mathrm{ALG} / \mathrm{CHI} / \mathrm{o}-\mathrm{GNR})_{100}(p<0.01)$. In the case of $(\mathrm{CHI} / \mathrm{ALG} /$ $\mathrm{CHI} / \mathrm{o}-\mathrm{GF})_{100}$ no significant differences are observed. On day 3 , significant differences are observed between (CHI/ALG/CHI/ o-GNR $)_{100}$ and $(\mathrm{CHI} / \mathrm{ALG} / \mathrm{CHI} / \mathrm{ALG})_{100}(p<0.05)$ and $(\mathrm{CHI} /$ ALG/CHI/o-GF $)_{100}(p<0.0001)$. Moreover, at this time point no significant differences are found between (CHI/ALG/CHI/o-GF) ${ }_{100}$ and TCPS but, significant differences are found in the case of $(\mathrm{CHI} / \mathrm{ALG} / \mathrm{CHI} / \mathrm{ALG})_{100}(p<0.0001)$. At day 7 , it is observed that
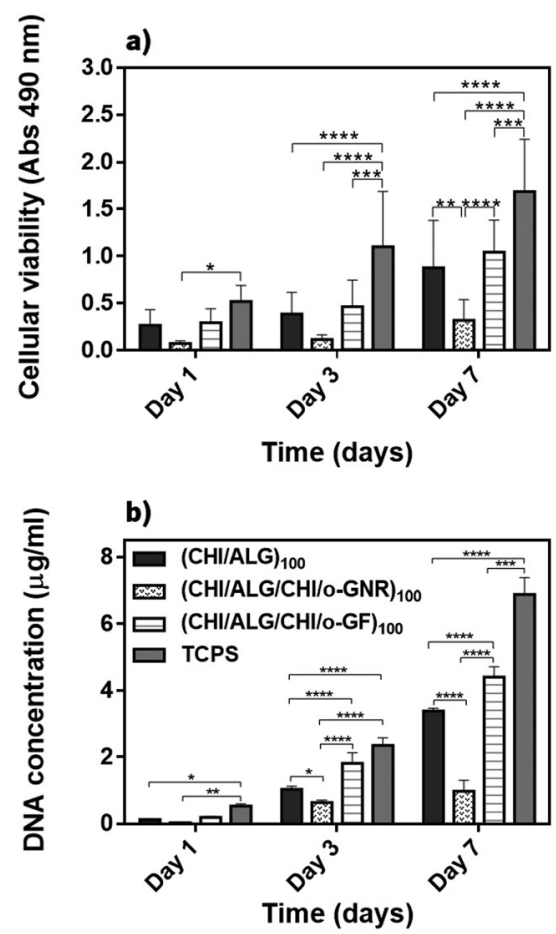

Fig. 13 (a) Cellular viability analysis for (CHI/ALG/CHI/ALG) $100,(\mathrm{CHI} / \mathrm{ALG}$ / $\mathrm{CHI} / \mathrm{O}-\mathrm{GNR})_{100}$ and (CHI/ALG/CHI/O-GF) 100 films using the MTS assay for 1, 3 and 7 days. (b) DNA quantification assay performed on (CHI/ALG/ $\mathrm{CHI} / \mathrm{ALG})_{100}$, (CHI/ALG/CHI/O-GNR) 100 and (CHI/ALG/CHI/O-GF) 100 . Significant differences were found for $\left.p<0.05\left(^{(*)}, p<0.01{ }^{(* *}\right), p<0.001{ }^{(* *}\right)$ and $p<0.0001^{(* * * *)}, N=3$. 
a pronounced increase in cell proliferation in the case of $(\mathrm{CHI} / \mathrm{ALG} / \mathrm{CHI} / \mathrm{ALG})_{100}$ leads to higher differences when compared to $(\mathrm{CHI} / \mathrm{ALG} / \mathrm{CHI} / \mathrm{o}-\mathrm{GNR})_{100}(p<0.0001)$. Moreover, the $(\mathrm{CHI} / \mathrm{ALG} / \mathrm{CHI} / \mathrm{o}-\mathrm{GF})_{100}$ condition is significantly different from $(\mathrm{CHI} / \mathrm{ALG} / \mathrm{CHI} / \mathrm{o}-\mathrm{GNR})_{100}(p<0.0001)$ and $(\mathrm{CHI} / \mathrm{ALG} / \mathrm{CHI} / \mathrm{ALG})_{100}$ $(p<0.0001)$.

The biological results demonstrated that the presence of o-GFs and o-GNRs in the polymeric matrix leads to different effects on the L929 cell behavior. The films with o-GFs present a better metabolic activity, adhesion and proliferation when compared to $(\mathrm{CHI} / \mathrm{ALG} / \mathrm{CHI} / \mathrm{ALG})_{100}$ and $(\mathrm{CHI} / \mathrm{ALG} / \mathrm{CHI} / \mathrm{o}-\mathrm{GNR})_{100}$. This improvement in cells' spreading and proliferation is probably the result of the hydrophilic behavior demonstrated previously, once it is known that cells adhere better to moderate hydrophilic surfaces rather than hydrophobic or super hydrophilic surfaces, creating a more suitable surface that may result in a fibronectin functionality maintenance. ${ }^{61,62}$ The roughness increase could also help fibronectin adsorption, as shown in some works. ${ }^{61,63}$ Moreover, the stiffness increase and water uptake decrease also contributed to an enhanced cellular behavior, since cells typically tend to prefer stiffer and lower hydrated films. ${ }^{64,65}$ These results are consistent with other works where GO was used as a filler of different polymeric matrices and where a benefic effect was verified when GO was incorporated. ${ }^{15,66,67}$ Thus, due to the significant increase of the cell proliferation, improved mechanical properties and enhanced thermal stability, these films may find a wide range of applications, such as: wound healing, and cardiac and bone engineering.

Unlike the previous films, (CHI/ALG/CHI/o-GNR) $)_{100}$ films resulted in a reduction of $\mathrm{L929}$ viability, adhesion and proliferation. Since these films present similar morphological, mechanical and physical properties to (CHI/ALG/CHI/o-GF) $)_{100}$ films, including WCA, stiffness and water uptake, the poor cell adhesion exhibited by these films is attributed to the o-GNR filler. In fact, this behavior may be related to the o-GNR structure. These GO derivatives have a ribbon-like structure while o-GFs possess a flake-like structure, thus we hypothesized that ribbon structures may cause physical damage on cell films, namely through the blade like action of such structures. Moreover, another factor that may have contributed to this behavior is the possibility that some MWNTs have not been totally unzipped and, hence, they do not exhibit a good surface functionalization, reducing their cytocompatibility. Along with this feature, the presence of some impurities on MWNTs including metal catalysts used for MWNT production that could be still entrapped on o-GNR structures could also reduce cytocompatibility. ${ }^{68}$

\section{Experimental}

\section{Materials}

MWNTs (purity approx. 90\%; average length $=1.5 \mu \mathrm{m}$ ) were supplied by Nanocyl ${ }^{\mathrm{TM}}$ (Belgium) and exfoliated graphite (EG) (purity approx. 99.5\%; average length $=9.9 \mu \mathrm{m}$ ) was obtained from Nacional de Grafite Ltda. (Brazil). To covalently functionalize the surface of MWNTs and EG, a chemical oxidation process was applied using: sulfuric acid $\left(\mathrm{H}_{2} \mathrm{SO}_{4} ; 95-97 \%\right)$, potassium permanganate $\left(\mathrm{KMnO}_{4}\right)$ analytical reagent grade, hydrogen peroxide analytical reagent grade $\left(\mathrm{H}_{2} \mathrm{O}_{2} ;>30 \% \mathrm{w} / \mathrm{v}\right)$, hydrochloric acid ( $\mathrm{HCl} ; 10 \% \mathrm{v} / \mathrm{v})$, all purchased from Fisher Scientific (UK), and distilled water (DW). Regarding the production of the FS films, CHI (medium molecular weight) was purchased from Sigma-Aldrich (Germany), with a degree of $\mathrm{N}$-deacetylation (DD) ranging from $75-85 \%$ and a viscosity of 200-800 cps. Prior to use, CHI was purified by a recrystallization process. Sodium alginate from brown algae (ALG) was purchased from Sigma-Aldrich, with a viscosity of 5 to $40 \mathrm{cps}$, and along with $\mathrm{CHI}$ it was used as a polymeric matrix.

\section{Synthesis of GO}

o-GFs were synthetized by a modified Hummers' method. Briefly, $400 \mathrm{~mL}$ of $\mathrm{H}_{2} \mathrm{SO}_{4}$ were added to $5 \mathrm{~g}$ of EG and stirred vigorously for $2 \mathrm{~h}$, in an ice-bath. $25 \mathrm{~g}$ of $\mathrm{KMnO}_{4}$ were slowly added to the previous solution and kept stirring overnight, at room temperature. Consecutively, the solution was transferred to an ice-bath and $300 \mathrm{~mL}$ of DW were slowly added. Then, $30 \mathrm{~mL}$ of $\mathrm{H}_{2} \mathrm{O}_{2}$ were added drop-by-drop and remained stirring for $30 \mathrm{~min}$. o-GNRs were obtained by a similar process. $4 \mathrm{~g}$ of MWNTs were added to $500 \mathrm{~mL}$ of $\mathrm{H}_{2} \mathrm{SO}_{4}$ and stirred for $4 \mathrm{~h}$. Then, in an ice bath, $32 \mathrm{~g}$ of $\mathrm{KMnO}_{4}$ were slowly added and kept stirring for $2 \mathrm{~h}$. The mixture was then heated up to $60{ }^{\circ} \mathrm{C}$ and stirred overnight. The same purification process was performed, including the addition of $300 \mathrm{~mL}$ of DW followed by $30 \mathrm{~mL}$ of $\mathrm{H}_{2} \mathrm{O}_{2}$, all steps were performed with the solution placed in an ice-bath. Afterwards, both solutions were transferred into $45 \mathrm{~mL}$ tubes and centrifuged at $3500 \mathrm{rpm}$ in a Labofuge 400 (Heraeus Instruments, USA), for $15 \mathrm{~min}$ and the supernatant was discarded. The precipitate was washed with DW for a total of 3 cycles. The resulting precipitate was then collected followed by the addition of $250 \mathrm{~mL}$ of $\mathrm{HCl}$ and it was left stirring for $15 \mathrm{~min}$. The mixture was once again centrifuged and washed for 3 cycles. After the centrifugation procedure, the supernatant was discarded and DW was added to the solid part and then filtered with a nylon film filter (Whatman, UK). The solid was dried for $48 \mathrm{~h}$ at $100{ }^{\circ} \mathrm{C}$ and finally milled. It is important to notice that at this stage, the resultant powder consists of o-EG and o-MWNTs, where the different layers of graphene were not completely separated. In order to achieve extensive exfoliation, o-EG and o-MWNTs were dispersed in DW and subjected to $4 \mathrm{~h}$ of ultrasound treatment in the ultrasonic bath, where exfoliation of the graphene layers was achieved resulting in o-GFs and o-GNRs from EG and MWNTs, respectively. The final o-GF and o-GNR suspensions presented a concentration of $0.25 \mathrm{mg} \mathrm{mL}^{-1}$ and the $\mathrm{pH}$ value was adjusted to a value of 8 .

\section{Structural characterization of GO}

Characterization of EG and MWNTs subjected to the modified Hummers' method. In a first step, EG and MWNTs synthetized by the modified Hummers' method were characterized by TGA and Raman spectroscopy. To evaluate the thermal stability of o-EG and o-MWNT powders, TGA was performed in Q500 equipment (TA Instruments, USA). The measurements 
were carried out in a nitrogen atmosphere in the temperature range of $40{ }^{\circ} \mathrm{C}$ to $800{ }^{\circ} \mathrm{C}$, and a scanning rate of $10{ }^{\circ} \mathrm{C} \mathrm{min}^{-1}$. To verify if the oxidation process was successful, EG, MWNT, o-EG and o-MWNT powders were placed over a glass coverslip and analyzed on a LabRAM HR Evolution Raman spectrometer (Horiba Scientific, Japan) using a laser excitation wavelength of $532 \mathrm{~nm}$. The results were analyzed using the LabSpec6 software.

Characterization of o-GFs and o-GNRs. For the chemical characterization of the as-synthetized GO, the o-GF and o-GNR solutions were analyzed by UV-vis spectrometry using a UV-2401 PC spectrometer (Shimadzu, Japan) on quartz cells with a path length of $1 \mathrm{~cm}$. FTIR analysis was performed on a 4100 FTIR Spectrometer (Jasco, Japan). For FTIR experiments, both o-GF and o-GNR solutions were drop-by-drop added to a $\mathrm{CaF}_{2}$ substrate and placed in a hot plate to evaporate the water, and finally a powder form of each solution was achieved. The spectrum was obtained by accumulating 32 spectral scans, in the spectral range of $500-4500 \mathrm{~cm}^{-1}$. The stability of the GO solutions was assessed using Zetasizer Nano-Zs equipment (Malvern Instruments, UK), and at least three zeta potential measurements were performed for each sample. The results presented are the average of these measurements.

The build-up of the multilayered films was followed in situ by quartz crystal microbalance with dissipation monitoring (QCM-D; Q-Sense). The $\Delta f$ and $\Delta D$ variations were recorded as a function of time and modeled in the QTools software using a Voigt based model. The QCM-D experiments started with alternate deposition of $\mathrm{CHI}$ and o-GFs or o-GNRs. Fresh polyelectrolyte solutions were deposited for $6 \mathrm{~min}$ and washed with DW for $4 \mathrm{~min}$ at a flow rate of $50 \mu \mathrm{L} \mathrm{min}{ }^{-1}$. All experiments were performed at $25{ }^{\circ} \mathrm{C}$ and in triplicate. Two different multilayer films, (CHI/o-GFs) and (CHI/o-GNRs), were obtained with three bilayers each.

\section{Production of FS multilayered films}

The production of the FS multilayered films was carried out on a polypropylene PP substrate. Prior to use, each substrate was washed with DW and ethanol followed by drying with a nitrogen flow. The PE solutions were prepared with a concentration of $2 \mathrm{mg} \mathrm{mL} \mathrm{mL}^{-1}$ at $\mathrm{pH}$ 5.5.

The assembly of each layer was achieved by alternate dipping of the support in different polyelectrolytes and GO solutions to form 100 tetralayers (tLs) of $\mathrm{CHI} / \mathrm{ALG} / \mathrm{CHI} / \mathrm{GO}$. The substrates were first dipped in the CHI solution for $6 \mathrm{~min}$ and then rinsed with DW for $4 \mathrm{~min}$. Subsequently, they were immersed in ALG solution for 6 min followed by rinsing with DW for $4 \mathrm{~min}$. After that, the substrate was dipped again in a CHI solution, rinsed with DW and allowed to dry at room temperature for $2 \mathrm{~min}$. Then, the substrate was immersed into a GO solution (o-GF or o-GNR at pH 8) for $6 \mathrm{~min}$ and rinsed with DW at $\mathrm{pH} 8$ for $4 \mathrm{~min}$. This procedure was repeated using a home dipping robot until the deposition of 100 tLs was achieved. These FS films will be named hereafter (CHI/ALG/CHI/o-GF) $)_{100}$ and (CHI/ALG/CHI/ o-GNR $)_{100}$. (CHI/ALG/CHI/ALG $)_{100}$ FS films were produced and used as controls. For that, the same procedure described above was used, replacing the deposition of o-GFs or o-GNRs with an ALG layer. The FS films were dried inside a plastic flask to minimize the shrinkage phenomenon. After drying, the films were easily detached from the substrate and kept for further analysis.

\section{SEM}

The morphology of the FS films was characterized, on both film sides, using a JSM-6010LV SEM (JEOL, Japan), operating at an accelerating voltage of $15 \mathrm{kV}$. Before each analysis, the samples were sputtered with a gold layer, using a sputter coater 108A (Cressington, UK). For the observation of the morphology across the thickness, the FS films were dipped in liquid nitrogen and cryo-fractured.

\section{AFM}

Dried FS films were imaged using Dimension Icon AFM equipment (Bruker, France) equipped with an air cantilever (SNL-10D) (Bruker, France) with a spring constant of $0.06 \mathrm{~N} \mathrm{~m}^{-1}$, operating in a ScanAsyst mode. The topography of the films was analyzed with $512 \times 512$ pixels $^{2}$ at line rates of $1 \mathrm{~Hz}$; AFM images with $5 \times 5 \mu^{2}$ were obtained, followed by root mean squared roughness $\left(R_{\mathrm{RMS}}\right)$ and average height value $\left(H_{\mathrm{AV}}\right)$ calculation. The analysis of the images was performed using NanoScope Analysis software and at least three measurements were carried out for each sample.

\section{Raman mapping}

For the observation of both o-GF and o-GNR distribution in the polymeric matrix, Raman mapping was performed using a LabRAM HR Evolution Raman spectrometer (Horiba Scientific, Japan) with a laser excitation wavelength of $785 \mathrm{~nm}$ and with a $100 \times$ objective lens. The spectra were recorded at room temperature and the final results were analyzed using LabSpec6 software.

\section{TGA}

Thermogravimetric analysis was performed on TA Q500 equipment (TA Instruments, USA). For that, approximately $4 \mathrm{mg}$ of each FS film was cut. The samples were heated under a constant flow of nitrogen from $40-800{ }^{\circ} \mathrm{C}$ at a heating rate of $10{ }^{\circ} \mathrm{C} \mathrm{min}^{-1}$. At least 3 measurements were performed for each sample.

\section{Contact angle measurements}

Static contact angle measurements were carried out on a contact angle analyzer from DataPhysics Instruments (Filderstadt, Germany), model OCA $15+$, with a high-performance image processing system. The sessile drop method was applied, and for that a drop $(5 \mu \mathrm{L})$ of water was deposited on the sample surface at room temperature and the image acquired as the drop came into contact with the surface. At least three measurements were performed on each film surface, and the results were analyzed using the SCA20 software.

\section{Water uptake}

The FS films produced were physically characterized in terms of water uptake by soaking the dry films, previously weighed, in phosphate buffer saline solution (PBS; Sigma, USA) at $37{ }^{\circ} \mathrm{C}$ for $5 \mathrm{~min}, 15 \mathrm{~min}, 30 \mathrm{~min}, 1 \mathrm{~h}, 3 \mathrm{~h}, 5 \mathrm{~h}, 7 \mathrm{~h}, 24 \mathrm{~h}$ and $48 \mathrm{~h}$. 
After each soaking period, the films were extracted from PBS solution and weighed, after the excess PBS was removed with a filter paper. The water absorption percentage was calculated according to eqn (1):

$$
\text { Water uptake }(\%)=\frac{W_{\mathrm{w}}-W_{\mathrm{d}}}{W_{\mathrm{d}}} \times 100
$$

where $W_{\mathrm{w}}$ is the weight of the films in the swollen state and $W_{\mathrm{d}}$ is the weight under dry conditions.

\section{Weight loss}

For the enzymatic biodegradation tests, samples with $10 \times$ $10 \mathrm{~mm}^{2}$ were pre-weighed and soaked in PBS with sodium azide $(0.02 \% \mathrm{w} / \mathrm{v},>99.5 \%)$ (Sigma-Aldrich, USA) and lysozyme from hen egg white (Sigma-Aldrich, UK) with a concentration of $13 \mathrm{mg} \mathrm{L}{ }^{-1}$. The vials were stored in an incubator for $0,1,3$, 7, 14 and 21 days at $37{ }^{\circ} \mathrm{C}$. After each incubation period, the samples were removed from the solution, washed with DW and dried at room temperature. The weight loss was calculated using eqn (2):

$$
\text { Weight loss }(\%)=\frac{\left(W_{\mathrm{i}}-W_{\mathrm{f}}\right)}{W_{\mathrm{i}}} \times 100
$$

where $W_{\mathrm{i}}$ is the initial dry weight of the sample and $W_{\mathrm{f}}$ is the final dry weight of the sample, at each incubation period. Three replicas were tested for each sample, and the average value was taken as the weight loss percentage.

\section{Mechanical characterization}

DMA was performed using a Tritec2000B DMA from Triton Technology (UK), in the tensile mode. The films were cut with $\approx 5 \mathrm{~mm}$ width. Prior to the DMA assays, the samples were soaked in a PBS solution overnight, to reach the swelling equilibrium. The thickness was measured along the sample length using a micrometer (Mitutoyo, Japan). FS films were clamped in the DMA apparatus with a grip distance of $10 \mathrm{~mm}$ and immersed in the PBS solution in a Teflon ${ }^{\circledR}$ reservoir. After equilibrating at $37{ }^{\circ} \mathrm{C}$, the DMA spectra were obtained performing a frequency scan from 0.1 to $10 \mathrm{~Hz}$. A static pre-load of $1 \mathrm{~N}$ was applied during the tests to keep the sample straight. At least three specimens were tested for each condition.

The tensile properties were investigated using universal mechanical testing equipment (Instron Ltd, UK). Specimens were cut into a rectangular shape $\left(5 \times 20 \mathrm{~mm}^{2}\right)$ and measurements were carried out using a $1 \mathrm{kN}$ load under a loading speed of $1 \mathrm{~mm} \mathrm{~min} \mathrm{~min}^{-1}$ and a gauge length of $10 \mathrm{~mm}$. At least five samples were tested for each composition, in order to obtain statistically significant data for the ultimate tensile strength and strain at failure. The samples were soaked overnight in a PBS solution to reach the swelling equilibrium, immediately before tensile testing.

\section{Biological assays}

Cell culturing and seeding. L929 mouse fibroblast lines (L929, European Collection of Cell Cultures) were used to test the in vitro biocompatibility of the $(\mathrm{CHI} / \mathrm{ALG} / \mathrm{CHI} / \mathrm{ALG})_{100}$,
$(\mathrm{CHI} / \mathrm{ALG} / \mathrm{CHI} / \mathrm{o}-\mathrm{GF})_{100}$ and $(\mathrm{CHI} / \mathrm{ALG} / \mathrm{CHI} / \mathrm{o}-\mathrm{GNR})_{100}$ films for 1, 3 and 7 days. Cells were cultured in complete Dulbecco's modified minimum essential medium (DMEM) supplemented with $3.7 \mathrm{~g} \mathrm{~L}^{-1}$ of sodium bicarbonate, $10 \%$ FBS and $1 \%$ penicillinstreptomycin ( $\mathrm{pH} \mathrm{7.4)}$, in $150 \mathrm{~cm}^{2}$ tissue culture flasks and incubated at $37{ }^{\circ} \mathrm{C}$ in a humidified air atmosphere of $5 \% \mathrm{CO}_{2}$. Every 2-3 days the medium was replaced.

Prior to cell seeding, samples with $10 \times 10 \mathrm{~mm}^{2}$ were sterilized by immersion in $70 \%(\mathrm{v} / \mathrm{v})$ ethanol for $2 \mathrm{~h}$ and then washed twice with sterile PBS. After this, the films were immersed in cell culture medium for complete swelling. The cells were seeded in the films (in triplicate) at a density of 50000 cells per sample and nourished with DMEM. The cultures were incubated at $37{ }^{\circ} \mathrm{C}$ in a humidified air atmosphere of $5 \% \mathrm{CO}_{2}$.

DAPI-phalloidin staining. The morphology and the viability of the cells were assessed using fluorescence staining with phalloidin tetramethylrhodamine and DAPI. At each time point DAPI (20 $\mathrm{mg} \mathrm{mL}^{-1}$, Sigma-Aldrich, USA) and phalloidin $\left(20 \mathrm{mg} \mathrm{mL}^{-1}\right.$, Sigma-Aldrich, USA) were used. Prior to staining, culture medium was removed and the films were washed with sterile PBS. Formalin (10\%, ThermoFisher) was added for $30 \mathrm{~min}$, to fix the cells of the above samples. After that, formalin was removed and the samples were washed with PBS. Following this, $1 \mathrm{~mL}$ of PBS with $10 \mu \mathrm{L}$ of phalloidin was added and kept at room temperature, protected from light, for $45 \mathrm{~min}$. Subsequently, the samples were washed with PBS and stained with $1 \mu \mathrm{L}$ of DAPI in $1 \mathrm{~mL}$ of PBS for $15 \mathrm{~min}$. After $15 \mathrm{~min}$, the samples were washed again with PBS and images were obtained using an inverted fluorescence microscope (Zeiss, Germany).

MTS assay. The metabolic activity of the L929 cells was measured using the MTS colorimetric assay (Cell Titer 96 AQueous One Solution Cell Proliferation Assay, Promega, USA). At each time point the samples were washed with PBS and then immersed in a MTS solution, prepared by using a 1:5 ratio of MTS reagent and serum free cell culture medium and let to incubate in this solution for $3 \mathrm{~h}$ at $37{ }^{\circ} \mathrm{C}$ with a humidified atmosphere containing $5 \% \mathrm{CO}_{2}$. Afterwards, $100 \mu \mathrm{L}$ (in triplicate) of each well were transferred to a new 96-well plate and finally the optical density (OD) was read at $490 \mathrm{~nm}$ on a multiwell microplate reader (Synergy HT, Bio-Tek Instruments). Three independent experiments were performed for the cytotoxicity tests.

DNA quantification. The seeding efficiency and proliferation of cells into the developed films were also investigated through the quantification of double-stranded DNA (dsDNA). The DNA was quantified at each time point (1, 3 and 7 days), using a PicoGreen dsDNA kit (Life Technologies, UK). Initially, cells were lysed by osmotic and thermal shock and consecutively the recovered supernatant was read on a microplate reader (BioTek, USA) using 485 and $528 \mathrm{~nm}$ as excitation and emission wavelengths, respectively. Triplicates were performed for each sample and the DNA amounts were calculated using a standard curve.

\section{Statistical analysis}

Data were expressed as average \pm standard deviation (SD) of at least three replicates. Normality tests were performed using Shapiro-Wilk tests. The normality of the population distribution 
was assessed, and parametric or non-parametric tests were used for normal or non-normal distributions, respectively. For the tensile tests and AFM assays the population was normally distributed and One way Anova followed by Tukey's test were used. In the particular case of the cellular assays, the Two way Anova was used. For WCA assays where the population was not normally distributed the Kruskal-Wallis test was employed. Statistical analysis was performed using the software GraphPad Prism 6.0 for Windows. Statistical significance was accepted for $p<0.05\left(^{*}\right)$. The error bars present in the graphics denote the standard deviation.

\section{Conclusions}

$(\mathrm{CHI} / \mathrm{ALG} / \mathrm{CHI} / \mathrm{o}-\mathrm{GF})_{100}$ and $(\mathrm{CHI} / \mathrm{ALG} / \mathrm{CHI} / \mathrm{o}-\mathrm{GNR})_{100}$ multilayered FS films were successfully developed by the LbL method. The composite films were rougher, more hydrophilic and less porous than the control (CHI/ALG/CHI/ALG) ${ }_{100}$ films. TGA allowed the approximate quantification of the o-GF and o-GNR overall weight content of $2.6 \%$ and $1.8 \%$, respectively. Moreover, the good dispersion of both nanofillers was confirmed by Raman spectroscopy mapping, which contributed to the films' improved dynamic and static mechanical properties. An increase in the resistance to degradability and decreased swelling in aqueous environments were also found. The biological assays indicated that the cells on the surface of the FS films with o-GFs were viable and were able to proliferate. Concerning the (CHI/ALG/CHI/o-GNR) $)_{100}$ films, further work needs to be carried out to understand their reduced cytocompatibility, in particular to ascertain if it is due to the lower hydrophilicity or if residual metal catalysts, originating on the carbon nanotubes used, are still present.

Ultimately, and according to the obtained results, it was demonstrated that the developed (CHI/ALG/CHI/o-GF) ${ }_{100}$ films exhibit interesting characteristics that can provide essential features for biomedical applications, including wound healing, and cardiac and bone engineering.

\section{Acknowledgements}

The authors acknowledge the Portuguese Foundation for Science and Technology (FCT) and the European program FEDER/ COMPETE for the financial support through project BioSeaGlue: EXPL/CTM-BIO/0646/2013 (FCOMP-01-0124-FEDER-041105) and for project PEst-C/CTM/LA0025/2013 (Strategic Project - LA 25 2013-2014). This work was also financially supported by FCT through the scholarships SFRH/BPD/96797/2013 granted to Sofia G. Caridade, SFRH/BD/97606/2013 granted to Maria Sousa, and SFRH/BD/87214/2012 granted to Eunice Cunha.

\section{References}

1 J. C. Slonczewski and P. R. Weiss, Phys. Rev., 1958, 109, 272-279.

2 A. K. Geim and K. S. Novoselov, Nat. Mater., 2007, 6, 183-191.
3 J. Chen, B. W. Yao, C. Li and G. Q. Shi, Carbon, 2013, 64, 225-229.

4 K. S. Novoselov, V. I. Fal'ko, L. Colombo, P. R. Gellert, M. G. Schwab and K. A. Kim, Nature, 2012, 490, 192-200.

5 A. S. Mayorov, R. V. Gorbachev, S. V. Morozov, L. Britnell, R. Jalil, L. A. Ponomarenko, P. Blake, K. S. Novoselov, K. Watanabe, T. Taniguchi and A. K. Geim, Nano Lett., 2011, 11, 2396-2399.

6 Y. Wang, Y. M. Li, L. H. Tang, J. Lu and J. H. Li, Electrochem. Commun., 2009, 11, 889-892.

7 L. Y. Feng, Y. Chen, J. S. Ren and X. G. Qu, Biomaterials, 2011, 32, 2930-2937.

8 B. A. Chen, M. Liu, L. M. Zhang, J. Huang, J. L. Yao and Z. J. Zhang, J. Mater. Chem., 2011, 21, 7736-7741.

9 L. Z. Feng, S. A. Zhang and Z. A. Liu, Nanoscale, 2011, 3, 1252-1257.

10 W. C. Lee, C. Lim, H. Shi, L. A. L. Tang, Y. Wang, C. T. Lim and K. P. Loh, ACS Nano, 2011, 5, 7334-7341.

11 H. N. Lim, N. M. Huang, S. S. Lim, I. Harrison and C. H. Chia, Int. J. Nanomed., 2011, 6, 1817-1823.

12 S. Park and R. S. Ruoff, Nat. Nanotechnol., 2009, 4, 217-224. 13 J. Kim, L. J Cote, F. Kim, W. Yuan, K. R. Shull and J. X. Huang, J. Am. Chem. Soc., 2010, 132, 8180-8186.

14 K. S. Hu, D. D. Kulkarni, I. Choi and V. V. Tsukruk, Prog. Polym. Sci., 2014, 39, 1934-1972.

15 K. Wang, J. Ruan, H. Song, J. L. Zhang, Y. Wo, S. W. Guo and D. X. Cui, Nanoscale Res. Lett., 2011, 6, 8.

16 S. F. Pei and H. M. Cheng, Carbon, 2012, 50, 3210-3228.

17 M. Ionita, M. A. Pandele and H. Iovu, Carbohydr. Polym., 2013, 94, 339-344.

18 A. M. Pandele, M. Ionita, L. Crica, S. Dinescu, M. Costache and H. Iovu, Carbohydr. Polym., 2014, 102, 813-820.

19 T. R. Nayak, H. Andersen, V. S. Makam, C. Khaw, S. Bae, X. F. Xu, P. L. R. Ee, J. H. Ahn, B. H. Hong, G. Pastorin and B. Ozyilmaz, ACS Nano, 2011, 5, 4670-4678.

20 S. R. Shin, B. Aghaei-Ghareh-Bolagh, X. G. Gao, M. Nikkhah, S. M. Jung, A. Dolatshahi-Pirouz, S. B. Kim, S. M. Kim, M. R. Dokmeci, X. W. Tang and A. Khademhosseini, Adv. Funct. Mater., 2014, 24, 6136-6144.

21 Y. Ikada and H. Tsuji, Macromol. Rapid Commun., 2000, 21, 117-132.

22 J. F. Mano, G. A. Silva, H. S. Azevedo, P. B. Malafaya, R. A. Sousa, S. S. Silva, L. F. Boesel, J. M. Oliveira, T. C. Santos, A. P. Marques, N. M. Neves and R. L. Reis, J. R. Soc., Interface, 2007, 4, 999-1030.

23 R. Jayakumar, M. Prabaharan, P. T. S. Kumar, S. V. Nair and H. Tamura, Biotechnol. Adv., 2011, 29, 322-337.

24 N. M. Alves and J. F. Mano, Int. J. Biol. Macromol., 2008, 43, 401-414.

25 I. Liakos, L. Rizzello, D. J. Scurr, P. P. Pompa, I. S. Bayer and A. Athanassiou, Int. J. Pharm., 2014, 463, 137-145.

26 G. Orive, S. Ponce, R. M. Hernandez, A. R. Gascon, M. Igartua and J. L. Pedraz, Biomaterials, 2002, 23, 3825-3831.

27 X. F. Huang, Y. F. Sun, J. Y. Nie, W. T. Lu, L. Yang, Z. L. Zhang, H. P. Yin, Z. K. Wang and Q. L. Hu, Int. J. Biol. Macromol., 2015, 75, 322-329. 
28 D. B. Tada, S. Singh, D. Nagesha, E. Jost, C. O. Levy, E. Gultepe, R. Cormack, G. M. Makrigiorgos and S. Sridhar, Pharm. Res., 2010, 27, 1738-1745.

29 J. Borges and J. F. Mano, Chem. Rev., 2014, 114, 8883-8942.

30 J. M. Silva, A. R. C. Duarte, S. G. Caridade, C. Picart, R. L. Reis and J. F. Mano, Biomacromolecules, 2014, 15, 3817-3826.

31 G. V. Martins, E. G. Merino, J. F. Mano and N. M. Alves, Macromol. Biosci., 2010, 10, 1444-1455.

32 S. G. Caridade, C. Monge, F. Gilde, T. Boudou, J. F. Mano and C. Picart, Biomacromolecules, 2013, 14, 1653-1660.

33 S. G. Caridade, C. Monge, J. Almodovar, R. Guillot, J. Lavaud, V. Josserand, J. L. Coll, J. F. Mano and C. Picart, Acta Biomater., 2015, 15, 139-149.

34 L. Tang, X. Li, D. Du and C. J. He, Prog. Nat. Sci., 2012, 22, 341-346.

35 R. Justin and B. Q. Chen, Carbohydr. Polym., 2014, 103, 70-80.

36 J. H. Li, N. Ren, J. C. Qiu, X. N. Mou and H. Liu, Int. J. Nanomed., 2013, 8, 3415-3426.

37 Y. Yin, K. Hu, A. Grant, Y. Zhang and V. Tsukruk, Langmuir, 2015, 31, 10859-10870.

38 R. Xiong, K. Hu, A. Grant, R. Ma, W. Xu, C. Lu, X. Zhang and V. Tsukruk, Adv. Mater., 2015, 28, 1501-1509.

39 Y.-Q. Li, T. Yu, T.-Y. Yang, L.-X. Zheng and K. Liao, Adv. Mater., 2012, 24, 3426-3431.

40 W. Qi, Z. Xue, W. Yuan and H. Wang, J. Mater. Chem. B, 2014, 2, 325-331.

41 K. Chen, B. Shi, Y. Yue, J. Qi and L. Guo, ACS Nano, 2015, 9, 8165-8175.

42 V. Singh, D. Joung, L. Zhai, S. Das, S. I. Khondaker and S. Seal, Prog. Mater. Sci., 2011, 56, 1178-1271.

43 X. X. Weng, Q. X. Cao, L. X. Liang, J. R. Chen, C. P. You, Y. M. Ruan, H. J. Lin and L. J. Wu, Talanta, 2013, 117, 359-365.

44 M. Venkanna and A. K. Chakraborty, American Institute Physics, 2014, 1591, 574-576.

45 Y. W. Zhu, S. Murali, W. W. Cai, X. S. Li, J. W. Suk, J. R. Potts and R. S. Ruoff, Adv. Mater., 2010, 22, 3906-3924.

46 B. Konkena and S. Vasudevan, J. Phys. Chem. Lett., 2012, 3, 867-872.

47 D. Li, M. B. Muller, S. Gilje, R. B. Kaner and G. G. Wallace, Nat. Nanotechnol., 2008, 3, 101-105.

48 R. R. Costa, A. I. Neto, I. Calgeris, C. R. Correia, A. C. M. Pinho, J. Fonseca, E. T. Oner and J. F. Mano, J. Mater. Chem. B, 2013, 1, 2367-2374.
49 S. S. Shiratori and M. F. Rubner, Macromolecules, 2000, 33, 4213-4219.

50 M. M. Gudarzi and F. Sharif, eXPRESS Polym. Lett., 2012, 6, 1017-1031.

51 J. M. Silva, S. G. Caridade, N. M. Oliveira, R. L. Reis and J. F. Mano, J. Mater. Chem. B, 2015, 3, 4555-4568.

52 S. Goenka, V. Sant and S. Sant, J. Controlled Release, 2014, 173, 75-88.

53 J. Hankiewi and E. Swiercze, Clin. Chim. Acta, 1974, 57, 205-209.

54 J. L. Zhang, F. Zhang, H. J. Yang, X. L. Huang, H. Liu, J. Y. Zhang and S. W. Guo, Langmuir, 2010, 26, 6083-6085.

55 H. L. Fan, L. L. Wang, K. K. Zhao, N. Li, Z. J. Shi, Z. G. Ge and Z. X. Jin, Biomacromolecules, 2010, 11, 2345-2351.

56 J. F. Mano, R. L. Reis and A. M. Cunha, Springer, 2002, 86, 139-164.

57 D. L. Han, L. F. Yan, W. F. Chen and W. Li, Carbohydr. Polym., 2011, 83, 653-658.

58 C. Y. Wan, M. Frydrych and B. Q. Chen, Soft Matter, 2011, 7, 6159-6166.

59 X. M. Yang, Y. F. Tu, L. A. Li, S. M. Shang and X. M. Tao, ACS Appl. Mater. Interfaces, 2010, 2, 1707-1713.

60 R. Costa, A. Costa, S. Caridade and J. Mano, Chem. Mater., 2015, 27, 7490-7502.

61 C. J. Wilson, R. E Clegg, D. I. Leavesley and M. J. Pearcy, Tissue Eng., 2005, 11, 1-18.

62 J. D. Mendelsohn, S. Y. Yang, J. Hiller, A. I. Hochbaum and M. F. Rubner, Rational Biomacromolecules, 2003, 4, 96-106.

63 L. Richert, P. Lavalle, E. Payan, X. Z. Shu, G. D. Prestwich, J. F. Stoltz, P. Schaaf, J. C. Voegel and C. Picart, Langmuir, 2004, 20, 448-458.

64 C. Picart, R. Elkaim, L. Richert, T. Audoin, Y. Arntz, M. D. Cardoso, P. Schaaf, J. C. Voegel and B. Frisch, Adv. Funct. Mater., 2005, 15, 83-94.

65 A. L. Hillberg, C. A. Holmes and M. Tabrizian, Biomaterials, 2009, 30, 4463-4470.

66 A. M. Pinto, S. Moreira, I. C. Goncalves, F. M. Gama, A. M. Mendes and F. D. Magalhaes, Colloids Surf., B, 2013, 104, 229-238.

67 Y. L. Chang, S. T Yang, J. H. Liu, E. Dong, Y. W Wang, A. N. Cao, Y. F. Liu and H. F. Wang, Toxicol. Lett., 2011, 200, 201-210.

68 S. K Smart, A. I. Cassady, G. Q. Lu and D. J. Martin, Carbon, 2006, 44, 1034-1047. 